\title{
Performance of Dual Purpose Barley Genotypes for Green Fodder by AMMI Analysis
}

\author{
Ajay Verma ${ }^{1 *}$, R. P. S. Verma ${ }^{2}$, A. S. Kharab ${ }^{1}$, Vishnu Kumar ${ }^{1}$ and R. K. Gupta ${ }^{1}$ \\ ${ }^{1}$ Indian Institute of Wheat and Barley Research, Karnal, Haryana (132 001), India \\ ${ }^{2}$ International Center for Agricultural Research for the Dry Areas (ICARDA), Rabat, Morocco
}

\section{Article History}

Manuscript No. AR1619

Received in $19^{\text {th }}$ June, 2016

Received in revised form $28^{\text {th }}$ September, 2016

Accepted in final form $4^{\text {th }}$ October, 2016

\section{Correspondence to}

EE-mail: verma.dwr@gmail.com

\section{Keywords}

AMMI analysis, IPCA's, MASV, ASV, D, YSI

\begin{abstract}
Highly significant effects were observed for green fodder yield of dual purpose barley for environments, genotypes and interactions. Environmental effects accounted for the major portion of the total variance as of $82.3 \%$. Significant interaction effects were partitioned further into IPCA1, IPCA2, IPCA3, IPCA4; which explained 30.4, 19.4, $14.8,13.2 \%$ respectively. MASV indicated that genotypes UPB 1035, BH 970, RD 2035, UPB 1034, RD 2857 and KB 1238 were stable; whereas, genotypes RD 2857 and RD 2035 were the stable genotypes with relatively more average yield. SIPC4 identified AZAD, RD 2856, UPB 1034, BH 970 and RD 2858 as stable genotypes. AMMI distance ranked genotypes in order of preference as RD $2035<\mathrm{BH} 970<\mathrm{RD}$ $2857<$ UPB $1035<$ UPB 1034. Least ASV score associated with UPB 1035, followed by UPB 1034, UPB 1036 and BH 971. Positive and negative IPCA1values had been observed for large number of genotypes. Genotype AZAD had large negative IPCA1 score along with positive IPCA4 as this reflected crossover type $\mathrm{G} \times \mathrm{E}$ interaction. RD 2715, RD 2857 and RD 2859 genotypes expressed yields greater than the overall mean and positive IPCA1 scores. Lower MASV observed for Vijapur, Banswara and Bikaner conditions where SIPC4 pointed towards Hisar, Bikaner and Varanasi as favorable locations. AMMI distance values identified Vijapur, Udaipur and Varanasi locations.
\end{abstract}

\section{Introduction}

Barley crop can be harvested as green fodder in rain fed, arid to semiarid conditions where other crops viz., barseem, oats, sugarcane etc. cannot be grown due to water shortage (Kharub et al., 2013). The crop had shown advantageous over oats due its dual utilization as green fodder for animal feed and grain crop for human consumption (Kumar et al., 2014). Dual barley cultivation provides nutrition to the livestock through its green fodder and grains can be harvested from regenerated crop (Kharub et al., 2013).

Methods to study Genotype-environment interaction varied from univariate to multivariate such as the additive main effect and multiplicative interaction (AMMI) analysis (Bavandpori et al., 2015). AMMI model is a hybrid model separates the additive variance from the multiplicative variance. The principal component analysis (PCA) applied to the interaction explains it in more detail the interaction pattern (Mortazavian et al., 2014). AMMI stability value (ASV) based on only two significant IPC's scores as well as the respective sum of squares (Sabaghnia et al., 2008). ASV observed useful for situations with relatively high total variation explained by two significant
IPCA's (Sabaghnia et al., 2012). Modified AMMI's stability value (MASV) benefited from four significant IPCs whenever, total of IPC1 and IPC2 variances were low.

Mohammadi et al. (2015) highlighted several advantages of MASV as compared to other AMMI based estimates. ASV and MASV had high significant correlation with grain yield (Karimizadeh et al., 2012). ASV and MASV parameters offer reliable statistic to describe $\mathrm{G} \times \mathrm{E}$ interaction (Adugna and Labuschange, 2003).

The prime objective of the present study was to stratify dual purpose barley genotypes by AMMI analysis based on their green fodder yield.

\section{Materials and Methods}

Sixteen barley genotypes (12 varieties and 4 checks) were evaluated under national varietal trials carried out under the All India coordinated wheat and barley improvement programme at eleven locations. The experiments were conducted during the crop season 2012-13 across locations, viz., Banswara, Bikaner, Durgapura, Faizabad, Hisar, Jalore, Kanpur, Kota, Udaipur, Varanasi and Vijapur. Details of studied genotypes and environmental conditions were presented in Table 
1 for reference. The randomized complete block design employed, with four replications. Cultural practices as zone ${ }^{-1}$ recommendations were followed to harvest good yield. AMMI analysis was carried out by Genstat software version 17.1 (VSN International).

Adugna and Labuschange (2002) introduced modified AMMI's stability value (MASV), based on all significant IPCs, for AMMI models for effective interpretation of $\mathrm{G} \times \mathrm{E}$ interactions as follows:

MASV $=\sqrt{\sum_{\mathrm{N}=1}^{\mathrm{N}-1}\left(\frac{\mathrm{SSIPC}_{\mathrm{n}}}{\mathrm{SSIPC}_{\mathrm{n}+1}}\right)\left(\mathrm{IPC}_{\mathrm{n}}^{2}+\mathrm{IP}_{1} \mathrm{C}^{2}\right)}$

Where, $\operatorname{SSIPC}_{n}$ and SSIPC $_{n+1}$ are sum of squares by the IPC $_{n}$, $\mathrm{IPC}_{\mathrm{n}+1}$ respectively

SIPC4 (sum of IPC scores) proposed by Sneller et al., 1997 based on AMMI analysis to identify stable genotypes as:

$\mathrm{SIPC}=\sum_{\mathrm{N}=1}^{\mathrm{N}-1} \gamma_{\text {in }} \lambda_{\mathrm{n}}^{0.5}$

Where, $g_{\text {in }}$ is the genotype eigen value for axis $n$ and $\lambda n$ is the eigen value of the IPC analysis axis $n$ as four significant IPC's were retained in the AMMI model.

AMMI stability value (ASV) based on the AMMI model's IPC1 and IPC2 scores for each genotype was calculated as follows (Purchase et al., 2000):

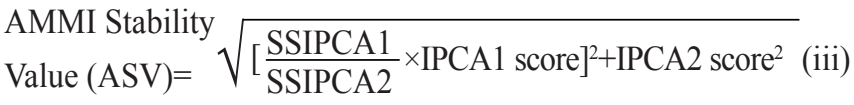

Where, SSIPCA1 and SSIPCA2 are sum of squares by the IPCA1, IPCA2 respectively. The lowest ASV value associated with stable performance of genotypes.

The AMMI distance statistic coefficient (D) (Zhang et al., 1998) was calculated as the distance of the Interaction Principal Component (IPC) point from the origin in space, for the significant IPCs, and $\gamma_{\text {is }}$ is the score of $i$-th genotype in IPC. The genotype with the lowest value of $\mathrm{D}$ considered as the most stable.

AMMI Distance $\left(\mathrm{D}_{i}\right)=\sqrt{\sum_{i=1}^{\mathrm{n}} \gamma_{i 3}^{2}}(\mathrm{i}=1,2,3, . \mathrm{n})$ (iv)

Yield stability index (YSI) incorporate mean yield and stability index of genotypes in single criteria and calculated as (Farshadfar et al., 2011):

YSI $=$ RASV $+R Y$

Where, RASV is the rank of AMMI stability value and RY is the rank of mean yield of genotypes (RY) across environments. Low values of index show desirable genotypes with high mean yield and stability.

\section{Results and Discussion}

\subsection{Analysis of variance}

Analysis revealed variances due to environments, genotypes and interactions were highly significant at $p<0.01$. Nearly

\begin{tabular}{|c|c|c|c|c|c|c|c|}
\hline Code & Genotype & Parentage & Code & Locations & Latitude & Longitude & $\begin{array}{l}\text { Altitude } \\
(\mathrm{m})\end{array}$ \\
\hline $\mathrm{G}_{1}$ & RD 2859 & K-551/PL-604//RD 2552 & $\mathrm{E}_{1}$ & Banswara & $23^{\circ} 55^{\prime} \mathrm{N}$ & $74^{\circ} 45^{\prime} \mathrm{E}$ & 216.4 \\
\hline $\mathrm{G}_{2}$ & RD 2552 C & RD 2035/DL 472 & $\mathrm{E}_{2}$ & Bikaner & $\begin{array}{c}28^{\circ} \\
02^{\prime} \mathrm{N}\end{array}$ & $73^{\circ} 31^{\prime} \mathrm{E}$ & 225.3 \\
\hline $\mathrm{G}_{3}$ & RD 2035C & RD 103/PL 101 & $\mathrm{E}_{3}$ & $\begin{array}{l}\text { Durga- } \\
\text { pura }\end{array}$ & $26^{\circ} 51^{\prime} \mathrm{N}$ & $75^{\circ} 47^{\prime} \mathrm{E}$ & 390 \\
\hline $\mathrm{G}_{4}$ & UPB 1036 & JYOTI/(CABUYA/JAZMIN//PETUNIA. 1) & $\mathrm{E}_{4}$ & Faizabad & $26^{\circ} 47^{\prime} \mathrm{N}$ & $82^{\circ} 12^{\prime} \mathrm{E}$ & 113 \\
\hline $\mathrm{G}_{5}$ & RD 2715 C & RD 387/BH 602//RD 2035 & $\mathrm{E}_{5}$ & Hisar & $29^{\circ} 10^{\prime} \mathrm{N}$ & $75^{\circ} 46^{\prime} \mathrm{E}$ & 215.2 \\
\hline $\mathrm{G}_{6}$ & UPB 1034 & RD 2624/DWR 46 & $\mathrm{E}_{6}$ & Jalore & $25^{\circ} 34^{\prime} \mathrm{N}$ & $72^{\circ} 62^{\prime} \mathrm{E}$ & 170.5 \\
\hline $\mathrm{G}_{7}$ & BH 971 & HBL 405/RD/2683 & $\mathrm{E}_{7}$ & Kanpur & $26^{\circ} 29^{\prime} \mathrm{N}$ & $80^{\circ} 18^{\prime} \mathrm{E}$ & 125.9 \\
\hline $\mathrm{G}_{8}$ & KB 1238 & K603/RD2552 & $\mathrm{E}_{8}$ & Kota & $25^{\circ} 21^{\prime} \mathrm{N}$ & $75^{\circ} 86^{\prime} \mathrm{E}$ & 259.7 \\
\hline $\mathrm{G}_{9}$ & BH 970 & HBL 276/RD/2683 & $\mathrm{E}_{9}$ & Udaipur & $24^{\circ} 34^{\prime} \mathrm{N}$ & $70^{\circ} 42^{\prime} \mathrm{E}$ & 582 \\
\hline $\mathrm{G}_{10}$ & RD 2858 & RD 2035/UBL-9//VMORALIS & $\mathrm{E}_{10}$ & Varanasi & $25^{\circ} 20^{\prime} \mathrm{N}$ & $83^{\circ} 03^{\prime} \mathrm{E}$ & 75.5 \\
\hline $\mathrm{G}_{11}$ & NDB 1570 & NDB 1020/LAKHAN & $\mathrm{E}_{11}$ & Vijapur & $23^{\circ} 35^{\prime} \mathrm{N}$ & $72^{\circ} 55^{\prime} \mathrm{E}$ & 41.1 \\
\hline $\mathrm{G}_{12}$ & UPB 1035 & $\begin{array}{l}\text { LAKHAN/(GIORIA-BAR/4/SOTOL//2762/ } \\
\text { BC-B/3/11012.2/...) }\end{array}$ & & & & & \\
\hline $\mathrm{G}_{13}$ & RD 2857 & RD 2620/NDB 1173//RD 2522 & & & & & \\
\hline $\mathrm{G}_{14}$ & AZAD C & K12/K19 & & & & & \\
\hline $\mathrm{G}_{15}$ & RD 2856 & RD 2620/NDB 1173//RD 2634 & & & & & \\
\hline $\mathrm{G}_{16}$ & NDB 1566 & BCB 128/NDB 940 & & & & & \\
\hline
\end{tabular}


$82.3 \%$ of the total sum of squares was attributable to environmental effects, $10.2 \%$ to $\mathrm{G} \times \mathrm{E}$ interaction and $2.9 \%$ to genotypic effects in AMMI analysis of variance for green fodder yield of sixteen dual purpose barley genotypes tested in eleven environments (Table 2). The large sum of squares for environments indicated that the environments were diverse, with differences among environmental means causing variation in forage yield (Abdipur and Vaezi, 2014). Highly significant $\mathrm{G} \times \mathrm{E}$ interaction for green fodder yield indicated the different performance of genotypes across environments. In spite of this high significance, the magnitude of the $\mathrm{G} \times \mathrm{E}$ interaction sum of squares was larger than that of genotypes, indicating the presence of large variation among the genotypes over environments.

The $\mathrm{G} \times \mathrm{E}$ interaction was partitioned into four significant interaction principal component analysis axis (IPCAs). First two IPCAs explained $30.4 \%$ and $19.4 \%$ of the variability and jointly accounted for only $49.8 \%$ of the interaction sum of squares.

\subsection{Modified AMMI stability value (MASV)}

Biplot visual interpretation of $\mathrm{G} \times \mathrm{E}$ interaction is not valid for more than two significant IPCs (Gauch et al., 2008). AMMI analysis indicated more complex $\mathrm{G} \times \mathrm{E}$ interaction and the graphical visualization of the genotypes in low dimensions is not valid to interpret $\mathrm{G} \times \mathrm{E}$ interaction by two IPCA's (Sabaghnia et al., 2012).

\begin{tabular}{|c|c|c|c|c|c|}
\hline \multicolumn{6}{|c|}{$\begin{array}{l}\text { Table 2: AMMI analysis of green fodder yield for dual barley } \\
\text { genotypes }\end{array}$} \\
\hline $\begin{array}{l}\text { Source of } \\
\text { variation }\end{array}$ & $\mathrm{DF}$ & MSS & VR & TSS $\%$ & $\begin{array}{c}\mathrm{G} \times \mathrm{E} \\
\%\end{array}$ \\
\hline Treatments & 175 & 14983 & $67.97^{* * *}$ & 95.47 & \\
\hline Genotypes & 15 & 5454 & $24.74^{* * *}$ & 2.98 & \\
\hline Environments & 10 & 226077 & $487.68^{* * *}$ & 82.31 & \\
\hline Block & 33 & 464 & & & \\
\hline Interactions & 150 & 1863 & $8.45^{* * *}$ & 10.18 & \\
\hline IPCA1 & 24 & 3537 & $16.04^{* * *}$ & & 30.37 \\
\hline IPCA2 & 22 & 2465 & $11.18^{* * *}$ & & 19.40 \\
\hline IPCA3 & 20 & 2063 & $9.36^{* * *}$ & & 14.76 \\
\hline IPCA4 & 18 & 2046 & $9.28^{* * *}$ & & 13.18 \\
\hline Residuals & 66 & 944 & & & \\
\hline Error & 495 & 220 & & & \\
\hline Total & 703 & 3907 & & & \\
\hline
\end{tabular}

DF: Degree of freedom; MSS: Mean Sum of squares; VR: Variance ratio; TSS: percentage of total sum of squares; $G \times E$ : percentage of $\mathrm{G} \times \mathrm{E}$ total sum of squares; ${ }^{* * *}$ denotes significant at $(p=0.001)$ level of significance
MASV used all four significant IPCs. The results of MASV indicated that genotypes $\mathrm{G}_{12}, \mathrm{G}_{9}, \mathrm{G}_{3}, \mathrm{G}_{6}, \mathrm{G}_{13}$ and $\mathrm{G}_{8}$ were most stable; whereas, genotypes $\mathrm{G}_{13}$, and $\mathrm{G}_{13}$ were the stable genotypes which had relatively more average yield (Table 3 ). MASV introduced some of the high yielding genotypes $\left(\mathrm{G}_{3}\right.$ and $\mathrm{G}_{13}$ ) as the most stable ones.

\subsection{SIPC4}

This would be useful in identifying stable genotypes as AZAD, RD 2856, UPB 1034, BH 970 and RD 2858 were the stable genotypes whereas RD 2715 and RD 2859 as unstable genotype (Table 3). It is interesting that high yield genotypes AZAD and RD 2858 had been identified by this parameter.

\subsection{AMMI stability index (D) incorporates}

The scores of significant four IPCA's towards the interaction sum of squares. The lower value of $\mathrm{D}$ associated stability across the tested environments and vice versa for instability (Zhang et al., 1998). The ranking of genotypes in ascending order of $D$ values are those in $\mathrm{G}_{3}(3.07)<\mathrm{G}_{9}(3.35)<\mathrm{G}_{13}(3.47)<\mathrm{G}_{12}$ (3.73) $<\mathrm{G}_{6}$ (3.79) (Table 3). Genotype $\mathrm{G}_{14}$ (AZAD), $\mathrm{G}_{15}$ (RD 2856 ) and $G_{4}$ (UPB 1036) showed larger $D$ values. More over the largest the negative value of IPCA1 score (-7.03) also exhibited by $\mathrm{G}_{14}$ (AZAD).

\subsection{AMMI stability value (ASV)}

ASV value is the distance from origin in a two dimensional scatter graph of IPCA1 against IPCA2 scores. Least ASV score associated with stable genotypes, accordingly genotype $\mathrm{G}_{12}$ (UPB 1035), followed by $\mathrm{G}_{6}$ (UPB 1034), $\mathrm{G}_{4}$ (UPB 1036) and $G_{7}\left(B H\right.$ 971) were stable (Table 3), while genotypes $G_{14}$ (AZAD), $\mathrm{G}_{15}$ (RD 2856) and $\mathrm{G}_{2}$ (RD 2552) were undesirable for green fodder yield.

\subsection{Yield stability index (YSI)}

The least YSI is considered as the most stable with high yield. Based on the YSI the most desirable genotype for selection is $\mathrm{G}_{13}$ (RD 2857), $\mathrm{G}_{5}$ (RD 2715) followed by $\mathrm{G}_{11}$ (NDB 1570) and $\mathrm{G}_{1}(\mathrm{RD} 2859)$.

\subsection{IPCAs interaction (crossover and non-crossover interactions)}

Green fodder yield of dual purpose barley genotype ranged from 169.8 to $127.5 \mathrm{q} \mathrm{ha}^{-1}$ with genotype RD2715 recorded highest yield and lowest yield shown by UPB 1035 .

Nearly $50 \%$ of genotypes showed positive and negative IPCA1 values for green fodder yield. Genotype $\mathrm{G}_{14}$ (AZAD) has large negative IPCA1 score also showed positive IPCA4 value (Table 3). This type of response is referred to as crossover $\mathrm{G} \times \mathrm{E}$ interaction. On the other hand, same sign or near zero scores represent a non-crossover interaction or a proportionate genotype response (Silveira et al., 2013). The genotypes with 


\begin{tabular}{llllllllllllllllllll}
\hline \multicolumn{10}{l}{ Table 3: AMMI estimates of green fodder yield for dual purpose barley genotypes } \\
\hline Code & Genotype & Gm & $\mathrm{R}_{\text {Gm }}$ & IPCA1 & IPCA2 & IPCA3 & IPCA4 & MASV & $\mathrm{R}_{\text {MASV }}$ & ASV & $\mathrm{R}_{\text {ASV }}$ & $\mathrm{D}$ & $\mathrm{R}_{\mathrm{D}}$ & SIPC4 & $\mathrm{R}_{\text {SIPC4 }}$ & YSI \\
\hline $\mathrm{G}_{1}$ & RD 2859 & 162.5 & 3 & 3.876 & 2.204 & 1.678 & 4.275 & 7.68 & 11 & 5.33 & 13 & 6.40 & 13 & 12.03 & 16 & 16 \\
$\mathrm{G}_{2}$ & RD 2552 & 154.5 & 9 & -4.153 & 1.717 & 2.348 & -1.181 & 6.85 & 8 & 5.47 & 14 & 5.21 & 9 & -1.27 & 9 & 23 \\
$\mathrm{G}_{3}$ & RD 2035 & 158.0 & 6 & -2.440 & 1.763 & -0.409 & 0.434 & 4.13 & 3 & 3.53 & 6 & 3.07 & 1 & -0.65 & 10 & 12 \\
$\mathrm{G}_{4}$ & UPB 1036 & 146.7 & 11 & -1.036 & 2.447 & -5.457 & 3.563 & 9.56 & 15 & 2.77 & 3 & 7.04 & 14 & -0.48 & 11 & 14 \\
$\mathrm{G}_{5}$ & RD 2715 & 169.8 & 1 & 3.276 & 1.649 & 3.520 & 1.485 & 7.18 & 9 & 4.42 & 10 & 5.30 & 10 & 9.93 & 15 & 11 \\
$\mathrm{G}_{6}$ & UPB 1034 & 141.3 & 15 & 1.211 & 0.127 & -2.046 & -2.954 & 4.46 & 4 & 1.52 & 2 & 3.79 & 5 & -3.66 & 3 & 17 \\
$\mathrm{G}_{7}$ & BH 971 & 142.5 & 14 & -0.077 & -2.905 & -2.554 & 3.423 & 6.71 & 7 & 2.91 & 4 & 5.17 & 8 & -2.11 & 6 & 18 \\
$\mathrm{G}_{8}$ & KB 1238 & 152.8 & 10 & 3.195 & -0.256 & -0.404 & -3.998 & 5.70 & 6 & 4.01 & 8 & 5.14 & 7 & -1.46 & 8 & 18 \\
$\mathrm{G}_{9}$ & BH 970 & 144.4 & 12 & -2.360 & 0.271 & 0.920 & -2.175 & 3.93 & 2 & 2.97 & 5 & 3.35 & 2 & -3.34 & 4 & 17 \\
$\mathrm{G}_{10}$ & RD 2858 & 156.6 & 7 & 3.730 & -0.401 & -4.231 & -2.000 & 8.01 & 12 & 4.68 & 11 & 6.00 & 12 & -2.90 & 5 & 18 \\
$\mathrm{G}_{11}$ & NDB 1570 & 162.4 & 4 & -1.181 & -4.021 & 3.741 & 1.415 & 8.44 & 13 & 4.28 & 9 & 5.79 & 11 & -0.05 & 12 & 13 \\
$\mathrm{G}_{12}$ & UPB 1035 & 127.5 & 16 & 0.341 & 0.956 & 0.309 & -3.572 & 3.91 & 1 & 1.05 & 1 & 3.73 & 4 & -1.97 & 7 & 17 \\
$\mathrm{G}_{13}$ & RD 2857 & 168.1 & 2 & 2.873 & 0.981 & 1.351 & 1.014 & 4.48 & 5 & 3.73 & 7 & 3.47 & 3 & 6.22 & 14 & 9 \\
$\mathrm{G}_{14}$ & AZAD & 158.7 & 5 & -7.033 & -1.785 & -1.281 & 0.447 & 9.41 & 14 & 8.98 & 16 & 7.38 & 16 & -9.65 & 1 & 21 \\
$\mathrm{G}_{15}$ & RD 2856 & 156.3 & 8 & 1.506 & -6.989 & 0.729 & 0.052 & 10.85 & 16 & 7.24 & 15 & 7.19 & 15 & -4.70 & 2 & 23 \\
$\mathrm{G}_{16}$ & NDB 1566 & 144.2 & 13 & -1.728 & 4.241 & 1.785 & -0.228 & 7.29 & 10 & 4.76 & 12 & 4.92 & 6 & 4.07 & 13 & 25 \\
\hline
\end{tabular}

Gm: Genotype mean yield; ASV: AMMI stability value; D: AMMI Distance; YSI: Yield stability index; $\mathrm{R}_{\mathrm{Gm}}$ : Genotype ranking based on $\mathrm{Gm} ; \mathrm{R}_{\mathrm{D}}$ : Genotype ranking based on $\mathrm{D} ; \mathrm{R}_{\mathrm{ASV}}$ : Genotype ranking based on ASV

lower IPCA1 scores would produce a lower absolute $\mathrm{G} \times \mathrm{E}$ interaction effect than those with higher absolute IPCA1 scores and have less variable yields (more stable) across genotypes (Oliveira et al., 2014). Genotypes $\mathrm{G}_{5}(\mathrm{RD} 2715), \mathrm{G}_{13}$ (RD 2857) and $\mathrm{G}_{1}(\mathrm{RD} 2859)$ with yields greater than the overall mean and positive IPCA1 scores.

\subsection{Environments classification based on AMMI analysis}

Environmental mean yields varied from 283.8 to $187 \mathrm{q} \mathrm{ha}^{-1}$ as variability observed both in main and interactions effects
(Table 4). Five out of eleven environments show negative IPCA1 scores while Jalore and Faizabad showed maximum positive IPCA1 scores (Table 4), while Bikaner and Faizabad had larger negative IPCA2 score and Kanpur and Varanasi possessed high negative IPCA3 scores. Kota and Jalore environments showed positive values for all IPCA's values with good green fodder yield. Lower MASV observed for Vijapur, Banswara and Bikaner conditions where, SIPC4 pointed towards Hisar, Bikaner and Varanasi as favorable locations. AMMI distance values identified Vijapur, Udaipur

\begin{tabular}{llccccccccc}
\hline \multicolumn{1}{l}{ Table 4: } & AMMI analysis of environments \\
\hline Code & Environment & Em & IPCA1 & IPCA2 & IPCA3 & IPCA4 & MASV & ASV & D & SIPC4 \\
\hline $\mathrm{E}_{1}$ & Banswara & 283.8 & -3.658 & -1.076 & 0.063 & 4.837 & 6.86 & 4.70 & 6.16 & 0.17 \\
$\mathrm{E}_{2}$ & Bikaner & 88.0 & -0.334 & -4.199 & 0.870 & -2.041 & 7.03 & 4.22 & 4.76 & -5.70 \\
$\mathrm{E}_{3}$ & Durgapura & 179.3 & -1.382 & 7.280 & 0.075 & -3.750 & 23.60 & 7.43 & 8.31 & 2.22 \\
$\mathrm{E}_{4}$ & Faizabad & 145.0 & 4.247 & -3.787 & 0.537 & -4.180 & 18.27 & 13.43 & 7.08 & -3.18 \\
$\mathrm{E}_{5}$ & Hisar & 105.2 & -8.869 & -0.409 & 0.127 & -0.174 & 27.20 & 27.18 & 8.88 & -9.33 \\
$\mathrm{E}_{6}$ & Jalore & 178.7 & 4.417 & 0.791 & 0.109 & 5.745 & 11.85 & 9.14 & 7.29 & 11.06 \\
$\mathrm{E}_{7}$ & Kanpur & 150.8 & 1.633 & 2.179 & -6.518 & -0.906 & 20.07 & 10.25 & 7.12 & -3.61 \\
$\mathrm{E}_{8}$ & Kota & 187.0 & 2.996 & 3.361 & 5.684 & 0.678 & 28.36 & 12.43 & 7.28 & 12.72 \\
$\mathrm{E}_{9}$ & Udaipur & 161.8 & -0.846 & -2.612 & 3.296 & -1.357 & 12.06 & 3.14 & 4.50 & -1.52 \\
$\mathrm{E}_{10}$ & Varanasi & 143.7 & 1.133 & -2.420 & -3.826 & 0.417 & 7.65 & 5.34 & 4.69 & -4.70 \\
$\mathrm{E}_{11}$ & Vijapur & 58.3 & 0.663 & 0.893 & -0.416 & 0.733 & 2.35 & 0.95 & 1.40 & 1.87 \\
\hline
\end{tabular}

Em: Environment mean; MASV: Modified AMMI stability value; SIPC4: Sum of 4 IPC's; ASV: AMMI stability value 
and Varanasi locations.

\section{Conclusion}

Sixteen dual barley genotypes were evaluated for green fodder yield under coordinated system at eleven locations across the country. Highly significant effects were observed for environments, genotypes and interactions. AMMI analysis indicated more complex $\mathrm{G} \times \mathrm{E}$ interaction and the graphical visualization by biplots would not interpret $\mathrm{G} \times \mathrm{E}$ interaction. MASV and SIPC4 based on four significant IPCs were useful and identified relatively the high yielding genotypes as the genotypes stable performance. Environments Vijapur, Banswara and Bikaner showed lower MASV while SIPC4 pointed towards Hisar, Bikaner and Varanasi as the favorable locations.

\section{Acknowledgement}

Support of Dr. A. Sarkar, ICARDA New Delhi and Dr. Murari Singh, Senior Biometrician, ICARDA Jordan sincerely acknowledged by authors. Authors are grateful to the staff of AICW and BIP centers to carry out the multi-environment testing of dual purpose barley genotypes across the country.

\section{References}

Abdipur, M., Vaezi, B., 2014. Analysis of the genotypeby-environment interaction of winter barley tested in the Rain-fed Regions of Iran by AMMI Adjustment. Bulgarian Journal of Agricultural Science 202, 421-427.

Adugna, W., Labuschagne, M.T., 2002. Genotype, environment interactions and phenotypic stability analyses of linseed in Ethiopia. Plant Breeding 121, 66-71.

Adugna, W., Labuschagne, M.T., 2003. Parametric and nonparametric measures of phenotypic stability in linseed (Linum usitatissimum L.). Euphytica 129, 211-218.

Bavandpori, F., Ahmadi, J., Hossaini, S., 2015. Yield stability analysis of bread wheat lines using AMMI model. Agricultural Communications 31, 8-15.

Farshadfar, E., Mahmodi, N., Yaghotipoor, A., 2011. AMMI stability value and simultaneous estimation of yield and yield stability in bread wheat (Triticum aestivum L.). Australian Journal of Crop Science 5, 1837-1844.

Gauch, H.G., Piepho, H.P., Annicchiarico, P., 2008. Statistical analysis of yield trials by AMMI and GGE: Further considerations. Crop Science 48, 866-889.

Karimizadeh, R., Mohammadi, M., Shefazadeh, M.K., Mahmoodi, A.A., Rostami, B., Karimpour, F., 2012. Relationship among and repeatability of ten stability indices for grain yield of food lentil genotypes in Iran. Turkish Journal of Field Crops. 17(1), 51-61.
Kharub, A.S., Verma, R.P.S., Kumar, D., Kumar, V., Selvakumar, R., Sharma, I., 2013. Dual purpose barley (Hordeum vulgare L.) in India. Performance and potential. Journal of Wheat Research 51, 55-58.

Kumar, V., Khippal, A., Singh, J., Selvakumar, R., Malik, R., Kumar, D., Kharub, A.S., Verma, R.P.S., Sharma, I., 2014. Barley research in India, Retrospect and amp; prospects. Journal of Wheat Research. 61, 1-20.

Mohammadi, M., Jafarby, J.A., Khanzadeh, H., Hosseinpur, T., Mohammad, M.P., Roustaii, M., Hosni, M.H., Mohammadi, P., 2015. Stability of grain yield of durum wheat genotypes by AMMI model. Agriculture and Forestry, Podgorica 61(3), 181-193.

Mortazavian, S.M.M., Nikkhah, H.R., Hassani, F.A., Sharifal-Hosseini, M., Taheri, M., Mahlooji, M., 2014. GGE biplot and AMMI analysis of yield performance of barley genotypes across different environments in Iran. Journal of Agricultural Science \& Technology 16, 609-622.

Oliveira, E.J., de, Freitas, J.P.X., de, Jesus, O.N.de, 2014. AMMI analysis of the adaptability and yield stability of yellow passion fruit varieties. Scientia Agricola 71(2), 139-145.

Purchase, J.L., Hatting, H., Vandeventer, C.S., 2000. Genotype $\times$ Environment interaction of winter wheat (Triticum aestivum L.) in South Africa, Stability analysis of yield performance. South African Journal of Plant and Soil 17, 101-107.

Sabaghnia, N., Mohammadi, M., Karimizadeh, R., 2012. The evaluation of Genotype $\times$ Environment interaction of durum wheat's yield using of the AMMI model. Agriculture and Forestry 55, 5-21.

Sabaghnia, N., Sabaghpour, S.H., Dehghani, H., 2008. The use of an AMMI model and its parameters to analyse yield stability in multi-environment trials. Journal of Agricultural Sciences 146, 571-581.

Silveira, L.C.I., Kist, V., Paula, T.O.M., Barbosa, M.H.P., Peternelli, L.A., Daros, E., 2013. AMMI analysis to evaluate the adaptability and phenotypic stability of sugarcane genotypes. Scientia Agricola 70, 27-32.

Sneller, C.H., Kilgore-Norquest, L., Dombek, D., 1997. Repeatability of yield stability statistics in soybean. Crop Science 37, 383-390.

VSN International, 2014. GenStat for Windows $17^{\text {th }}$ Edition. VSN International, Hemel Hempstead, UK.

Zhang, Z., Lu, C., Xiang, Z.H., 1998. Analysis of variety stability based on AMMI model. Acta Agronomica Sinica 24, 304-309. 